\title{
Multiple arboviral infections during a DENV-2 outbreak in Solomon Islands
}

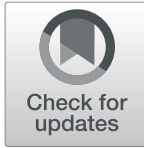

\author{
Andrew Waleluma Darcy ${ }^{1}$, Seiji Kanda ${ }^{{ }^{*}}$ (D), Tenneth Dalipanda², Cynthia Joshua ${ }^{2}$, Takaki Shimono ${ }^{1}$, \\ Pheophet Lamaningao', Nobuyuki Mishima and Toshimasa Nishiyama'
}

\begin{abstract}
Background: Solomon Islands, a country made up of tropical islands, has suffered cyclic dengue fever (DF) outbreaks in the past three decades. An outbreak of dengue-like illness (DLI) that occurred in April 2016 prompted this study, which aimed to determine the population's immunity status and identify the arboviruses circulating in the country.

Methods: A household survey, involving 188 participants in two urban areas (Honiara and Gizo), and a parallel hospital-based clinical survey were conducted in April 2016. The latter was repeated in December after a surge in DLI cases. Arbovirus IgG ELISA were performed on the household blood samples to determine the prevalence of arboviruses in the community, while qPCR testing of the clinical samples was used to identify the circulating arboviruses. Dengue virus (DENV)-positive samples were further characterized by amplifying and sequencing the envelope gene.

Results: The overall prevalence rates of DENV, Zika virus, and chikungunya virus were $83.4 \%, 7.6 \%$, and $0.9 \%$, respectively. The GPCR positivity rates of the clinical samples collected in April 2016 were as follows: DENV 39.6\%, Zika virus $16.7 \%$, and chikungunya virus $6.3 \%$, which increased to $74 \%, 48 \%$, and $20 \%$ respectively in December 2016. The displacement of the circulating serotype-3, genotype-1, with DENV serotype 2, genotype cosmopolitan was responsible for the outbreak in 2016.

Conclusions: A DENV outbreak in Solomon Islands was caused by the introduction of a single serotype. The high prevalence of DENV provided transient cross-protection, which prevented the introduction of a new serotype from the hyperendemic region for at least 3 years. The severe outcomes seen in the recent outbreak probably resulted from changes in the causative viruses and the effects of population immunity and changes in the outbreak pattern. Solomon Islands needs to step up surveillance to include molecular tools, increase regional communication, and perform timely interventions.
\end{abstract}

Keywords: Dengue fever, Arbovirus, Seroprevalence, Molecular, Immunity

\section{Introduction}

Dengue fever (DF) is the most prevalent mosquito-borne viral infection in tropical and subtropical regions. It is estimated to cause 50-100 million symptomatic infections annually [1]. The complex interactions between the virus and the human population have resulted in an

\footnotetext{
* Correspondence: kandas@hirakata.kmu.ac.jp

${ }^{1}$ Department of Hygiene and Public Health, Kansai Medical University,

Hirakata, Japan

Full list of author information is available at the end of the article
}

unpredictable disease evolution and variable clinical outcomes associated with the infection. The majority of infections are mild and self-limiting, but a small number progress to severe clinical manifestations, which can lead to severe organ complications and even death [2-4]. Dengue virus (DENV) is a Flavivirus from the Flaviviridae family. Its RNA genome is approximately $11-\mathrm{kb}$ long and contains an open reading frame, which codes for three structural and five non-structural proteins. The virus has four distinct

(c) The Author(s). 2020, corrected publication 2020. Open Access This article is licensed under a Creative Commons Attribution 4.0 International License, which permits use, sharing, adaptation, distribution and reproduction in any medium or format, as long as you give appropriate credit to the original author(s) and the source, provide a link to the Creative Commons licence, and indicate if changes were made. The images or other third party material in this article are included in the article's Creative Commons licence, unless indicated otherwise in a credit line to the material. If material is not included in the article's Creative Commons licence and your intended use is not permitted by statutory regulation or exceeds the permitted use, you will need to obtain permission directly from the copyright holder. To view a copy of this licence, visit http://creativecommons.org/ licenses/by/4.0/. 
antigenic serotypes and several genotypes, which produce different outcomes during outbreaks [5-7].

Most global DF cases occur in the Asia-Pacific region [1]. Countries in Southeast Asia (SE Asia) are generally more urban and have high population densities, while the Pacific Island countries (PICTs) are rural, and their populations are scattered across many islands. Previous DF outbreaks in the PICTs were caused by a single serotype, which occurred every 5 to 10 years [8]. On the other hand, in SE Asia all four DENV serotypes are circulating, and a 3-year wave-like outbreak pattern, in which the disease emanates from a central metropolitan city, is seen. There have been very few quality descriptive studies of DF conducted in the PICTs, resulting in a paucity of information about the magnitudes and drivers of DF epidemics in this region. The available studies were mostly based in a clinic setting or involved specific groups like a blood donor population $[9,10]$. The principal vectors of DF, Aedes aegypti (Linnaeus, 1762) and Aedes albopictus (Skuse, 1894), are present in both SE Asia and the PICTs.

Solomon Islands is an archipelago, consisting of a double chain of islands, located in the southwest Pacific region. It has a population of more than half a million people. It shares a border with Papua New Guinea, and the densely populated region of SE Asia is located to the west (Fig. 1). While the majority of the population live in rural areas and are involved in subsistence agriculture, fast-growing unregulated urban settlements are also common.

The first reported DF outbreak in Solomon Islands occurred in Honiara, the capital city of Solomon Islands, in 1982, but it was only confirmed serologically in 1992 [11]. A 10-year inter-epidemic cyclic pattern was observed until 2008, when DENV-4 first started to circulate the region [12]. A subsequent outbreak in 2013 was more severe, resulting in the first reported deaths [13]. This outbreak was unique, as it lasted longer than usual, i.e., previous outbreaks lasted 2 years, but the 2013 outbreak lasted until early 2016. This, in addition to the global expansion and reported occurrence of Zika virus (ZIKV) and chikungunya virus (CHKV) infections in the region $[14,15]$, prompted us to carry out this study.

The study objectives were to estimate the seroprevalence of arboviruses in the urban population of Solomon Islands while using qPCR to determine the circulating viruses from the clinical samples; furthermore, to characterize and compare the dengue virus isolated from our study to previous published isolates from the region using the phylogenetic tree analysis.

\section{Materials and methods}

\section{Data collection}

Suspected cases of DF were reported syndromically as dengue-like illness (DLI), which was defined as the sudden onset of fever, testing negative for malaria, and

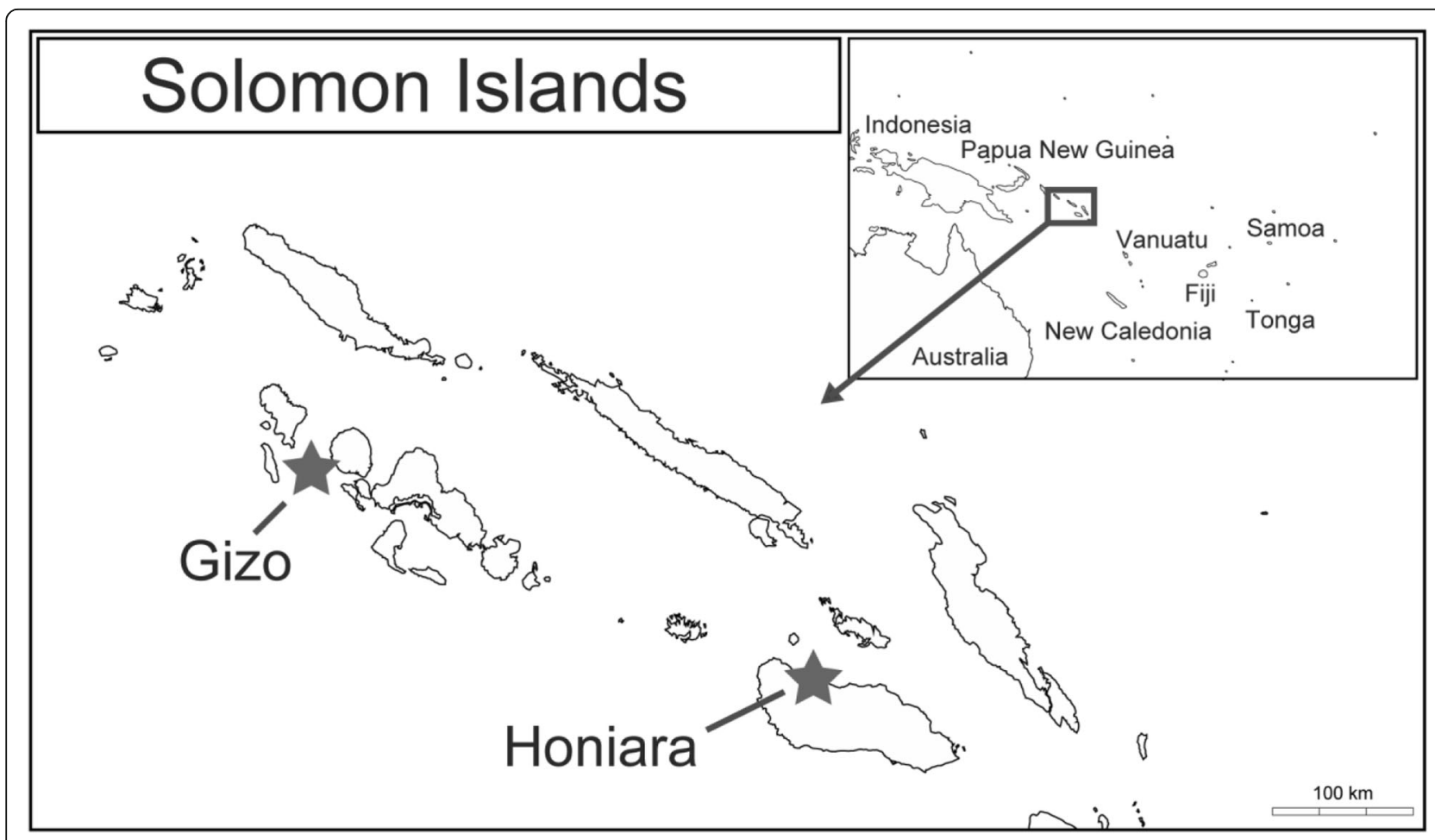

Fig. 1 Map of Solomon Islands. A partial map of Solomon Islands, showing Honiara and Gizo, where the study was performed is shown 
exhibiting one or two clinical manifestations of DF, as described previously [16]. In order to obtain a complete picture, we only included the clinics in Honiara, including Gizo, that started reporting from 2013 to 2016. This ensured that we would be able to detect trends using consistent and complete datasets. The virological investigations involved 2-weeklong blood sample collection periods (in April or December 2016), during which blood samples were collected from DLI patients that visited the hospitals in Honiara and Gizo.

The household seroprevalence study was performed in April 2016 in Gizo (Western Province) and a community settlement (Tuvaruhu) that was representative of Honiara. Each of the subjects that gave their consent filled out a questionnaire, before approximately $500 \mu \mathrm{L}$ of blood was collected in a pediatric tube, containing ethylenediaminetetraacetic acid (EDTA), using the finger prick method (Becton Dickinson collection system). The blood samples were brought back to the hospital laboratory and processed by centrifugation at $13000 \mathrm{rpm}$ for 10 min to separate the plasma. The samples were then transported to our laboratory overseas, where they were stored at $-20^{\circ} \mathrm{C}$, before being used for various enzymelinked immunosorbent assays tests.

\section{Serological tests}

To determine the seroprevalence of arboviruses in the household study, tests for IgG antibodies against various arboviruses were performed using commercially available ELISA. These included tests for anti-DENV IgG antibodies (Vircell, Granada, Spain), anti-ZIKV IgG antibodies (MyBioSource Inc., CA, USA), and anti-CHIKV IgG antibodies (Abcam, Cambridge, UK). The controls provided with the kits and the cutoff values listed in the associated information were used to determine the results, as recommended by the manufacturers. The clinical samples from recent DLI cases were tested using non-structural protein-1 (NS1)/IgM/IgG combo rapid diagnostic test (RDT) kits for DENV. Tests for the other arboviruses were performed on selected December samples using commercial IgM ELISA kits (ZIKV IgM ELISA, MyBioSource Inc., and CHIKV IgM ELISA, Abcam).

\section{Molecular testing}

The qPCR screening was performed using cDNA extracted from $200 \mu \mathrm{L}$ of the serum samples from the patients with suspected DF. The cDNA was synthesized using the random primer protocol in the ReverTra Ace- $\alpha-^{-}$system (Toyobo, Osaka, Japan), as recommended by the manufacturer. The cDNA samples were stored at $-20^{\circ} \mathrm{C}$, before being used for various molecular tests. The qPCR screening used previously described DENV serotype-specific and ZIKV-specific primers (Table 1) with some modifications [17-19]. A $10-\mu \mathrm{L}$ reaction mixture, containing $0.2 \mu \mathrm{M}$ of each forward and reverse primer, $5 \mu \mathrm{L}$ of $2 \times$ SsoAdvanced universal SYBR Green supermix taq (Bio-Rad Laboratories, Hercules, CA), and $1 \mu \mathrm{L}$ template, was used together with the Rotor-Gene qPCR system (Qiagen, Hilden, Germany). The qPCR setup involved an initial temperature of $95^{\circ} \mathrm{C}$ for $30 \mathrm{~s}$, followed by 40 cycles of $15 \mathrm{~s}$ at $95^{\circ} \mathrm{C}$, and $30 \mathrm{~s}$ at $57^{\circ} \mathrm{C}$. To detect CHKV, the primers listed in Table 1 were designed based on the conserved region of the envelope gene, which was based on an alignment that included the Papua New Guinea (PNG) sequence (MF773569). The primer was first characterized by making 10 -fold serial dilutions of $9.6 \times 10^{5}$ copies of the E1 gene using the qPCR conditions described above. The amplification curve and $T_{\mathrm{m}}$ peak value were analyzed to calculate the correlation coefficient and consensus peak values of the primer. Sequence confirmation of $10 \%$ of the qPCR products was then performed to further validate the primer.

\section{DENV envelope gene sequencing and phylogenetic tree analysis}

The DENV envelope genes were investigated using cDNA templates from patients that were found to be positive for DENV in the clinical surveys conducted in Gizo and Honiara. The templates were amplified using TksGflex $^{\mathrm{TM}}$ DNA polymerase (TaKaRa Bio, Shiga, Japan) and previously described overlapping primers for DENV-2 and DENV-3 [20]. The PCR products were then cycle-sequenced using the BigDye Terminator cycle sequencing kit (version 3.1), before being sequenced on the ABI3130xl automated sequence analyzer (Thermo

Table 1 The primers used in the qPCR screening of the arbo-viruses

\begin{tabular}{lll}
\hline & Forward primers & Reverse primers \\
\hline DENV1 & ATA CCY CCA ACA GCA GGA ATT & AGC ATR AGG AGC ATG GTC AC \\
DENV2 & TGG ACC GAC AAA GAC AGA TTC TT GY CCY TGC AGC ATT CCA A \\
DENV3 & AAG ACG GGA AACCG TCT ATC AA & TTG AGA ATC TCT TCG CCA ACT G \\
DENV4 & CCA TCC CAC CRA CAG CAG G & CAA GAT GTT CAG CAT GCG GC \\
ZIKAV & AAG TTT GCA TGC TCC AAG AAA AT & CAG CAT TAT CCGGTA CTC CAG AT \\
CHIKV & CAA GAA AAT AAC ATC ACT GTA ACT & TCC AGG CTG AAG ACA TTG \\
\hline
\end{tabular}


Fisher Scientific, Inc.). The final 1485-bp sequence for DENV-2 and the final 1479-bp sequence for DENV-3 were obtained by manually assembling the overlapping sequences in BioEdit (version 7.19) [21]. Our study sequences were uploaded to the DNA Data Bank of Japan (DDBJ) under accession numbers LC440471 to LC440484. These sequences were combined with those circulating SE Asia, Australia, and PICTs (from GenBank) to construct a phylogenetic tree using the maximum likelihood (ML) method in the software MEGA (version 7) [22]. Multiple full-envelope nucleotide sequences were aligned using Clustal W, which is integrated into the MEGA software, while evolutionary distances were computed using the recommended Tamura-Nei + G model. The reliability of the ML analysis was evaluated via a bootstrap test of 3000 replications. A different genotype from that of the interest group was set as an outgroup in each of the dengue trees.

\section{Data analysis}

Descriptive statistical analyses were performed using the SPSS statistical software (version 18.0; SPSS Inc., IL, USA), and individual subjects were used as statistical units. Multinomial logistic regression analysis was performed to analyze the associations between selected variables and dengue infections. The prevalence rates for each variable were also determined, together with $95 \%$ confidence intervals $(95 \% \mathrm{CI})$. A catalytic model with a constant force was used to calculate the force of infection (FOI), which was determined using the ML method, as described previously $[23,24]$.

\section{Results}

\section{Honiara sentinel dengue reporting}

The sentinel clinic data for DLI reported for Honiara, which covered the period from 2013 to 2016, are shown in Fig. 2. The graph shows that two outbreaks with very similar outbreak patterns occurred within 3 years, i.e., in 2013 and 2016. The outbreaks involved a sharp increase in the number of DLI cases in the first month and peaked in the subsequent 3 months. The 2016 sentinel data represented $45 \%$ of all DLI syndromic cases, as reported previously [16]. The 2016 outbreak differed from the previous outbreak in that it started in August rather than in January. Furthermore, the continuous persistent occurrence of DLI was seen before the spike in August 2016.

\section{Household survey results}

The household survey involved 188 participants, who were recruited from Honiara $(n=78)$ or Gizo $(n=110)$. No refusals to participate were recorded in this study. There were slightly more females than males (male:female $=1: 1.27)$. The subjects' mean age was 21.1 years (95\% CI 18.7-23.4; range: from 1 to 83 years old). The most common main source of income for the surveyed households was being employed in the private sector (43\%), followed by being employed in the public sector (36\%).

The overall seroprevalence of the DENV, as measured by the rate of positive anti-DENV IgG antibody ELISA results, was $83.4 \%$ (95\% CI 77.7-88.3\%) (Table 2). The prevalence of the DENV was slightly higher in Honiara

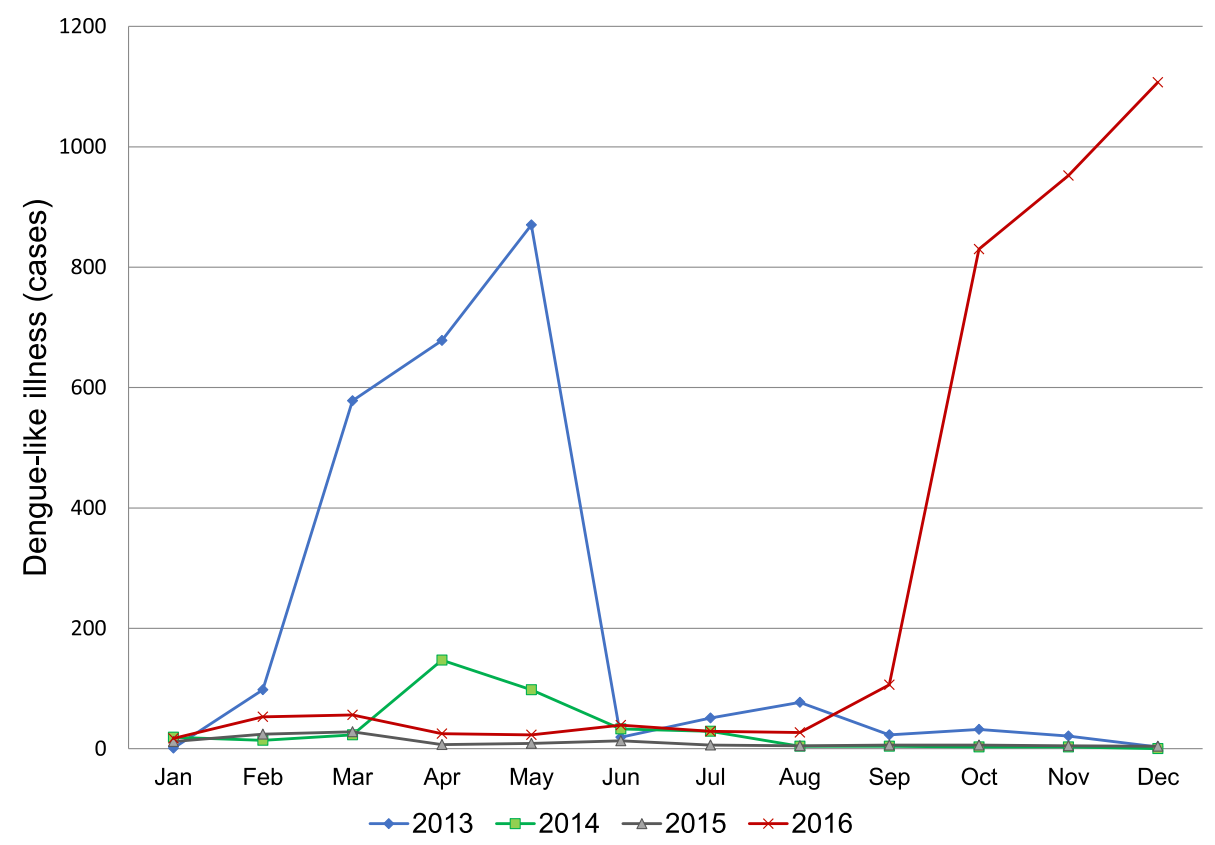

Fig. 2 The number of cases detected in Honiara during the sentinel clinic surveillance from 2013 to 2016 
(88.4\%) than in Gizo (80.0\%), but the difference was not significant $(p=0.14)$. The prevalence of the DENV differed significantly between females (88.6\%) and males $(77.1 \%)(p$ value $=0.04)$. Neither the main household source of income nor recalled illnesses in the last 12 months significantly affected the prevalence of the DENV. The prevalence of the DENV increased with age, with the lowest prevalence rate $(61.5 \%)$ seen in the 1-5 years age group and plateaued in the 16-20 years age group (Fig. 3). The mean ages of the subjects that tested positive and negative for anti-DENV IgG antibodies were 23.0 years and 11.7 years, respectively. The difference between the two groups (11.3 years) was significant. The FOI, which was defined as the annual risk of infection by any DENV serotype among DENV-naïve individuals, was $16.4 \%$ in the $1-20$ years age group.
The prevalence results for the other arboviruses were 7.6\% for the ZIKV and 0.9\% for the CHKV (Table 2).

\section{Clinical survey results}

The high positivity rate for anti-DENV IgG antibodies (77.9\%) and the high DENV positivity rate detected in the qPCR analysis of the clinical samples (76.3\%) were indicative of a high number of secondary infections in the 2016 outbreak. Our high prevalence results appeared to support the idea that IgG is a useful serological marker of past exposure to the DENV.

Among the 48 samples tested in April 2016, all of the detected DENV belonged to the DENV-3 serotype. In December, however, the dominant serotype detected in 131 tested samples was DENV-2 (74\%), although 5 samples were co-infected with the DENV-3 serotype.

Table 2 The results of the household study in April 2016 showing the various arbovirus prevalence and characterization of the dengue infection in our study population

\begin{tabular}{llll}
\hline Variable & $\mathrm{N}$ & Positive (prevalence \%) & $95 \% \mathrm{Cl}(\%)$ \\
\hline A. Arboviruses & & & $(77.7-88.3)$ \\
Dengue & 188 & $158(83.4)$ & $(4.1-11.6)$ \\
Zika & 172 & $13(7.6)$ & $(0.0-8.6)$ \\
Chikungunya & 122 & $1(0.9)$ &
\end{tabular}

\section{B. Dengue prevalence}

\section{Site}

Gizo

Honiara

Gender

Male

Female

Age group

1-5

6-10

11-15

16-20

Main household source of income

Private sector

Government

Self employed

Others

12 months illness recall

Was ill

Had fever

Had malaria

Had dengue fever

Force of infection
(71.3-87.0)

(79.2-94.6)

(66.6-85.6)

(80.9-88.6)

(40.6-79.8)

0.00

(53.3-90.2)

0.02

(61.1-91.2)

0.04

(75.1-99.8)

0.90

(75.9-92.0)

(64.6-85.9)

0.61

(72.0-98.9)

0.16

(61.5-98.5)

0.49

(74.8-90.3)

0.60

(66.7-87.3)

0.07

(73.8-93.6)

0.36

$\begin{array}{ll}(59.5-98.3) & 0.64\end{array}$ 


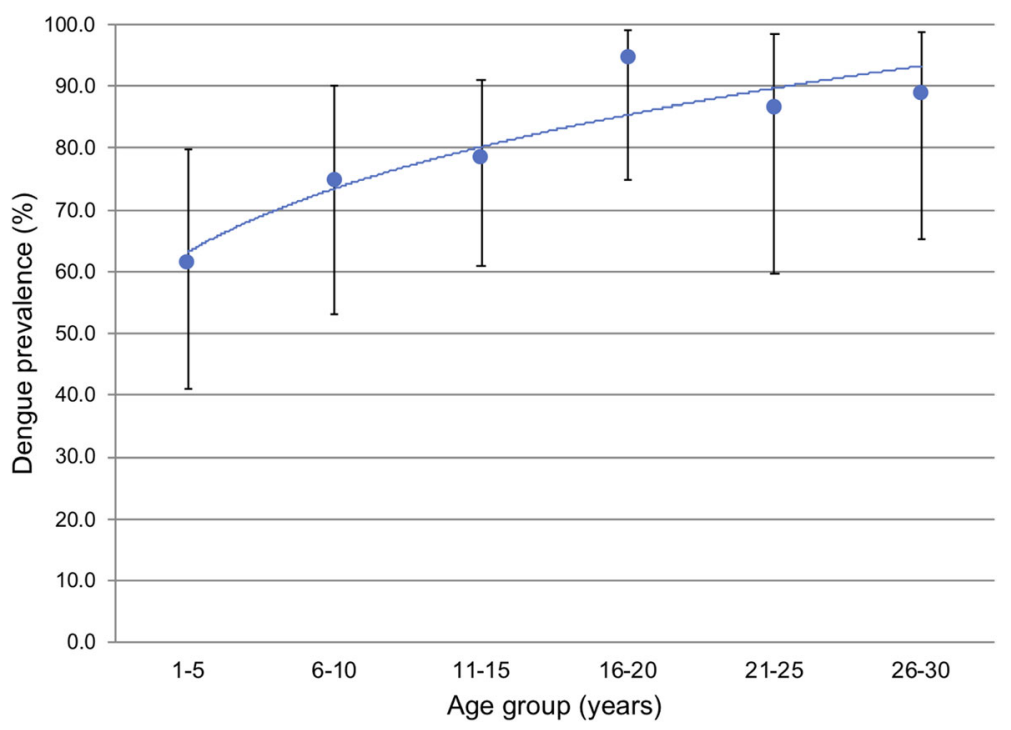

Fig. 3 The prevalence of the DENV in different age groups in the household survey

The qPCR-based ZIKV detection rate was $16.7 \%$ in April, and it increased to $41 \%$ in December, while the qPCR-based CHKV detection rate increased from 6.3\% in April to $20.1 \%$ in December. Further analysis of the qPCR results showed that triple infections with DENV, ZIKV, and CHKV were detected in $15.8 \%$ of the December samples. Analysis of the December samples also revealed that there were only $4 \mathrm{CHKV}$-positive and 9 ZIKV-positive samples among the 34 DENV-negative samples.

\section{Sensitivity and specificity of the RDT for DENV}

Among the clinical samples collected in December, a subset of 109 samples was used to calculate the sensitivity and specificity of the DENV RDT compared with the qPCR reference test (Table 3).

The DENV RDT combo kit included tests for NS1, IgM, and IgG. The sensitivity and specificity of the NS1based RDT were found to be $60 \%$ and $84 \%$, respectively. When the NS1-based test was combined with the IgMbased test, the sensitivity of the RDT increased to $66 \%$, but its specificity was reduced to $69 \%$. The sensitivity and specificity of the IgG-based RDT were $46 \%$ and $50 \%$, respectively, which the kit manufacturer's information suggested was indicative of a high rate of secondary infections.

Table 3 Dengue RDT sensitivity and specificity on 109 clinical samples

\begin{tabular}{lllll}
\hline Dengue assay & Sensitivity & Specificity & PPV & NPV \\
\hline RDT NS1 & $49 / 82(60 \%)$ & $22 / 26(84 \%)$ & $49 / 53(92 \%)$ & $22 / 55(40 \%)$ \\
RDT IgM or NS1 & $54 / 82(66 \%)$ & $18 / 26(69 \%)$ & $54 / 62(87 \%)$ & $18 / 46(39 \%)$ \\
RDT IgG & $26 / 82(46 \%)$ & $13 / 26(50 \%)$ & $26 / 39(67 \%)$ & $13 / 69(19 \%)$ \\
\hline
\end{tabular}

DENV envelope gene phylogenetic analysis

\section{Dengue virus serotype 3}

The phylogenetic tree for DENV-3 shown in Fig. 4 was constructed using 73 sequences from SE Asia, Australia, and the Pacific region.

The Solomon Island sequences were isolated from 2012 to 2016 and included 5 isolates from our study in April. The sequences in the tree were classed under DENV serotype 3, genotype-1. The PICT lineage, which included isolates from Solomon Islands, Fiji, Vanuatu, Samoa, and Nauru, shared a bootstrap value of 84 and circulated the region. They shared a common linkage with isolates from PNG (KT758738/2011 and KT758776/2014). An ancestral link with a bootstrap value of 95 to an isolate dating back to 2007 (KY794787/2007) was shared by all isolates found in PNG, Australia, and the PICTs. They also shared ancestral links with the isolates that had been circulating from 1989 to1996. The ancestral links also showed that SE Asia played an important role in the evolution of DF and its introduction to the PICTs.

\section{Dengue virus serotype 2}

The DENV-2 phylogenetic tree shown in Fig. 5 was constructed using the 7 sequences we isolated in December and 75 sequences from SE Asia, Australia, and the PICTs, which were obtained from GenBank.

They were all classified as DENV-2, genotypecosmopolitan. There were two distinct DENV-2 lineages circulating the Pacific region in 2016. The Solomon Island samples were all very similar and had a very strong bootstrap value of 99 , which indicated that the virus was introduced at a single point and was circulating for a very short period of time. The 


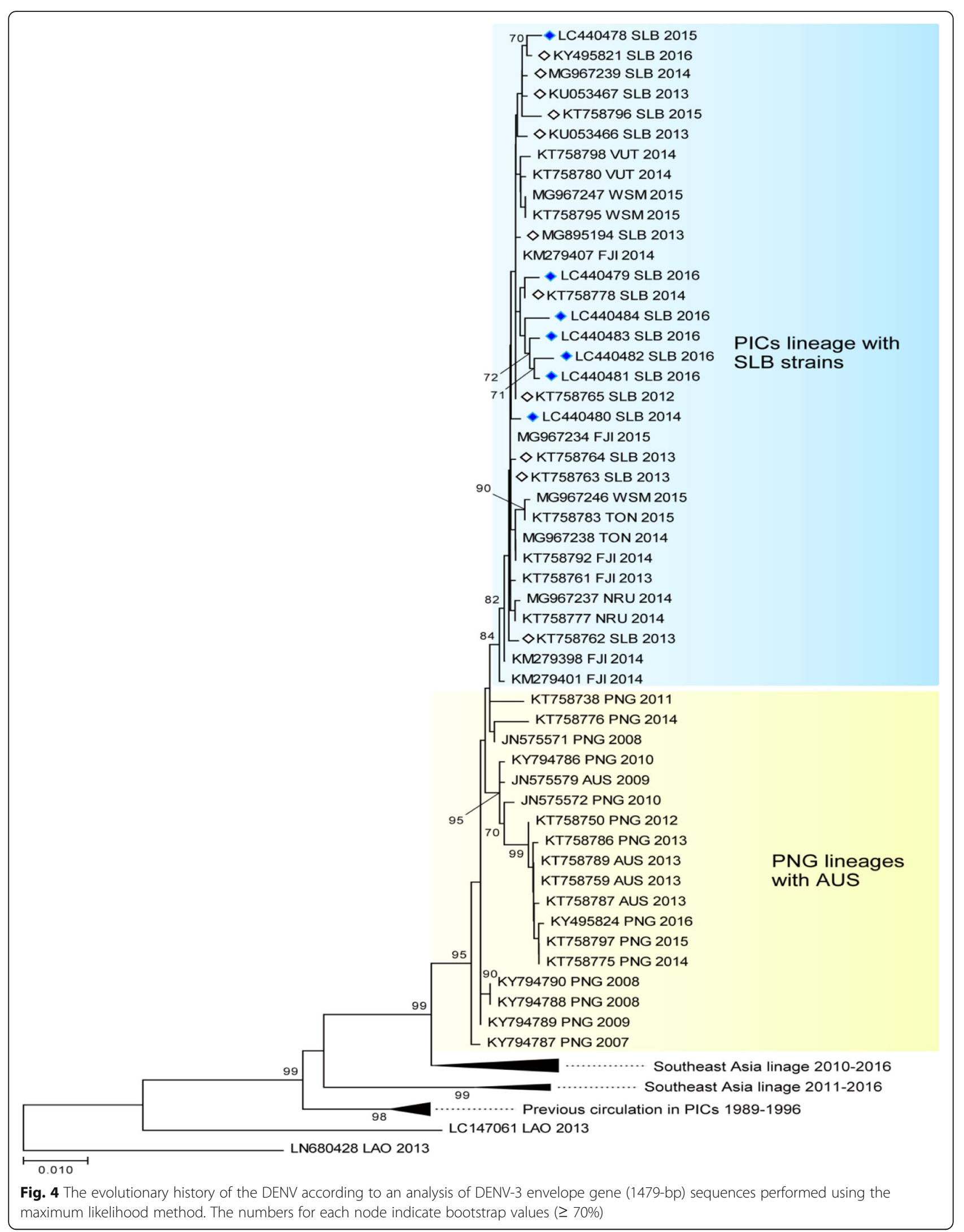




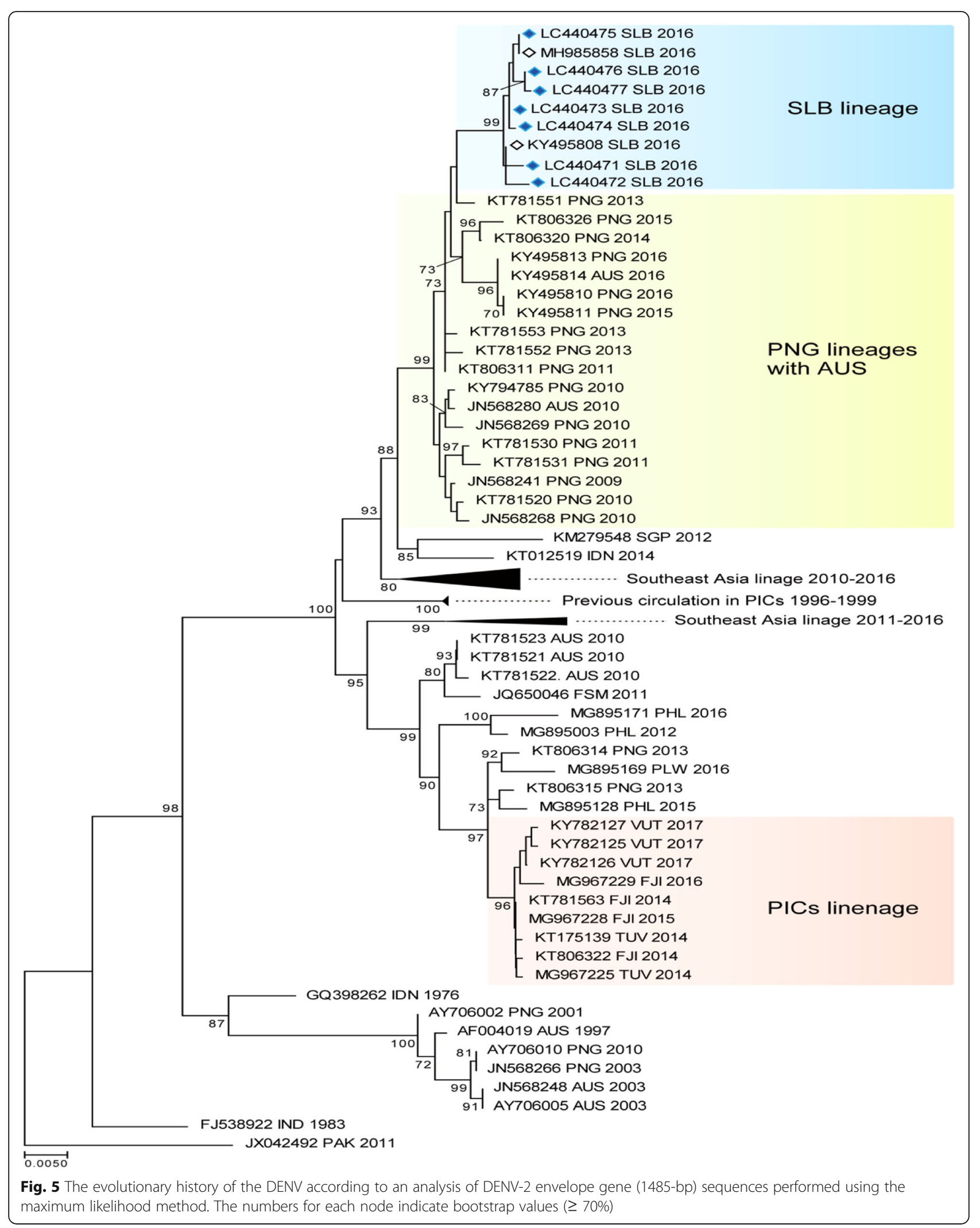


lineage shared an ancestral link with a bootstrap value of 99 with the PNG/Australia lineages (2013-2016). The other PICT lineage, which had a bootstrap value of 96, circulated in Fiji, Tuvalu, and Vanuatu from 2014 to 2017 and shared an ancestral link with a bootstrap value of 99 with sequences from PNG/ Australia (2010-2013). The geographical distribution of the virus, which included the northern Pacific region (FSM 2011 and Palau 2016), suggested that there were multiple entry routes, possibly including the Philippines (2015-2016). Only the Solomon Island lineage (2016) shared common ancestry with a virus that was previously circulating the Pacific region (1996-1999).

\section{Discussion}

The prevalence of DENV in our study was comparable to those seen in other studies conducted in the region. For example, the prevalence of DENV was reported to be $95.6 \%$ in Samoa, 83\% in PNG, and 83-96\% in French Polynesia $[9,10,25]$. These values were similar to those reported in Asian countries: Bangladesh 80-83.3\% [26], the Philippines 79.2\% [27], and Thailand 79.2\% [28].

Based on the syndromic data obtained in 2013, the high anti-DENV IgG antibody prevalence rate found in our study before the 2016 surge must have arisen during the first 3 months of an outbreak. This would have resulted in at least two-thirds of the population being exposed and becoming immune to the circulating serotype. A study conducted in Bangkok suggested that such exposure induces 3 years transient cross-protection against other DENV serotypes [29]. This would have provided herd immunity, which would have helped control the outbreak and could have been responsible for the alternative serotype outbreak pattern seen in the country [30]. It was also suggested that DENV-immune individuals are cross-protected against ZIKV [31], which would probably explain the low prevalence of ZIKV in April 2016 despite its circulation in the country in 2015 (GenBank KX 216632) [32].

The high qPCR-based DENV detection rate seen in our DENV-immune study population pointed to a high secondary DENV infection rate during the 2016 outbreak. Secondary infections involve heterologous DENV infections and are associated with an increased risk of severe DF [33, 34]. The DENV responsible for the new infection will trigger antibody production from preexisting plasma cells, but these antibodies will not be able to neutralize the newly introduced serotype. The non-neutralizing binding of the antibodies to the virus results in the formation of a complex that binds to the Fcy receptor, which is expressed on monocytes, macrophages, and dendritic cells, to facilitate antibodydependent enhancement [35]. This process promotes virus production and an altered immune response, which is linked with severe DF.

The use of NS1-based DENV RDT in a resource-poor setting was very useful for diagnosis and management. However, the sensitivity value of the NS1-based RDT (60\%) was low compared to the $95 \%$ sensitivity value reported in the previous DENV-3 outbreak in 2013 [36]. Secondary infections and the DENV serotype are important factors affecting the diagnostic sensitivity of NS1-based RDT [37, 38]. In our study, the NS1-based RDT was found to have lower sensitivity for the DENV2 serotype than for the previously reported DENV-3.

The phylogenetic tree analysis and the serotypespecific qPCR results indicated that there was a single DENV-3 serotype in circulation from 2012 to 2016 in Solomon Islands. The newly introduced DENV-2 serotype in 2016 was responsible for the spike in cases seen in the latter part of 2016. This successful introduction was unique, as it was the first time that two serotypes were found to be co-circulating in the country. The cocirculation of multiple serotypes is a feature of endemic settings and was also recently reported in neighboring PNG [39]. The co-circulation of DENV-1 and DENV-4 has also been reported in New Caledonia [8], suggesting that such co-circulation is a potential threat in the region.

The presence of two lineages of the DENV-2 cosmopolitan serotype circulating the Pacific region in 2016 confirmed the heterogeneous nature of the virus [40] and the importance of monitoring the outbreak potential of different lineages. It also highlighted the importance of performing molecular sequencing analysis to identify genotype and subgenotype lineages. The DENV has probably been introduced into the PICTs multiple times from multiple sources. Our study, however, seemed to highlight ancestral linkages to PNG where the circulation of multiple serotypes and the formation of local lineages had been described [39]. Better molecular surveillance in PNG will enable more accurate prediction of DENV outbreaks in the Pacific region.

Recent improvements in airline travel links to the PICTs will make it easier to introduce new viruses into the region as airline travel was reported to increase the risk of DF spreading in Asia [41]. It is important for countries to have good surveillance mechanisms for both diseases and their vectors to enable timely interventions in future outbreaks.

\section{Strengths and limitations}

The seroprevalence study was initially designed to explore the population's immunity to DENV in order to predict its outbreak potential. The sample size was small, as it was based on the high DENV positivity rate (approximately $30 \%$ ) seen during the last outbreak. It 
was therefore not ideal for investigating the ZIKV or $\mathrm{CHKV}$, which have low prevalence rates. As the clinical study was initially only planned to involve molecular virological surveillance, it lacks demographic and clinical information. This also explains why the April 2016 samples were not subjected to serological testing. However, this study provided important information that will aid understanding of the unique outbreak pattern seen in this small population.

\section{Conclusion}

This study found that the 2016 DLI outbreak in Solomon Islands was caused by multiple circulating arboviruses. The displacement of a single serotype (DENV-3) by a newly introduced one (DENV-2) was the predominant cause of the 2016 DLI outbreak, but there was evidence of ZIKV and CHKV co-circulating. The outbreak pattern suggests that natural population immunity is still the main control mechanism and that the population will always be vulnerable to vector-borne diseases. There is a need to step up vector-control activities and community mobilization to reduce the threat of such diseases in Solomon Islands. We recommend that Solomon Islands needs to increase its capacity for disease surveillance to include molecular screening of different arboviruses and some capacity to perform regular sequencing of the envelope genes of viral isolates. We also recommend the surveillance of disease vectors and their insecticide-resistance status. The communication of this information within the region will enable each country/ territory to prepare as best as they can for the next outbreak.

\section{Abbreviations \\ DF: Dengue fever; DLI: Dengue-like illness; ELISA: Enzyme-linked immunosorbent assays; DENV: Dengue virus; PICTs: Pacific Island countries; SE Asia: Southeast Asia; CHKV: Chikungunya virus; ZIKV: Zika virus; EDTA: Ethylenediaminetetraacetic acid; RDT: Rapid diagnostic test; PNG: Papua New Guinea; E1 gene: Envelope-1 gene; DDBJ: DNA Data Bank of Japan; ML: Maximum likelihood; FOl: Force of infection; HRC: Health Research Committee}

\section{Acknowledgements}

We would like to thank Miss Kaoru Miyata, Central Research Laboratory of Kansai Medical University, for her help with the DNA sequencing. We also thank our partners in the Solomon Islands Ministry of Health and Medical Services (MHMS), including the surveillance unit, the National Vector Borne Disease Control Program (NVBCP), and participating hospitals and laboratories, for their input during the sample collection process.

\section{Authors' contributions}

NT conceptualized the project, while the rest of the research team supported the planning and implementation of the study. DT, JC, and DAW mobilized the field team and supported the sampling fieldwork and blood collection. KS, ST, MN, and LP supervised the clinical and laboratory work and analyzed the results. DAW drafted the manuscript, while all of the authors have reviewed the final draft and agreed to its publication.

\section{Funding}

This research was partially funded by grant D2 from the Kansai Medical University. The funders had no role in the study design, data collection or analysis, the decision to publish, or the preparation of the manuscript.

\section{Availability of data and materials \\ Not applicable}

\section{Ethics approval and consent to participate}

The study protocol was reviewed, and ethical approval was obtained from the Solomon Island National Health Research Committee (HRC13/11) and Kansai Medical University research ethics committee, Japan (No1616).

\section{Consent for publication}

Not applicable.

\section{Competing interests}

The authors confirm that there are no known conflicts of interest associated with this publication and there has been no significant financial support for this work that could have influenced its outcomes.

\section{Author details}

${ }^{1}$ Department of Hygiene and Public Health, Kansai Medical University, Hirakata, Japan. ${ }^{2}$ Ministry of Health \& Medical Services, Honiara, Solomon Islands.

Received: 23 January 2020 Accepted: 23 April 2020

Published online: 15 May 2020

\section{References}

1. WHO. Global strategy for dengue prevention and control, 2012-2020. Diseases DoCoNT, editorAugust 2012.

2. Guzman MG, Harris E. Dengue. Lancet. 2015;385(9966):453-65.

3. Tewari K, Tewari W, Mehta R. Clinical and hematological profile of patients with dengue fever at a tertiary care hospital - an observational study. Mediterr J Hematol Infect Dis. 2018;10(1):e2018021

4. Wei HY, Shu PY, Hung MN. Characteristics and risk factors for fatality in patients with dengue hemorrhagic fever, Taiwan, 2014. Am J Trop Med Hyg. 2016;95(2):322-7.

5. Holmes EC. RNA virus genomics: a world of possibilities. J Clin Invest. 2009; 119(9):2488-95.

6. Rico-Hesse R. Dengue virus virulence and transmission determinants. Curr Top Microbiol Immunol. 2010;338:45-55.

7. Steel A, Gubler DJ, Bennett SN. Natural attenuation of dengue virus type-2 after a series of island outbreaks: a retrospective phylogenetic study of events in the South Pacific three decades ago. Virology. 2010;405(2):505-12.

8. Dupont-Rouzeyrol M, Aubry M, O'Connor O, Roche C, Gourinat AC, Guigon A, et al. Epidemiological and molecular features of dengue virus type-1 in New Caledonia, South Pacific, 2001-2013. Virol J. 2014;11:61.

9. Aubry M, Teissier A, Huart M, Merceron S, Vanhomwegen J, Mapotoeke M, et al. Seroprevalence of dengue and chikungunya virus antibodies, French Polynesia, 2014-2015. Emerg Infect Dis. 2018;24(3):558-61.

10. Duncombe J, Lau C, Weinstein P, Aaskov J, Rourke M, Grant R, et al. Seroprevalence of dengue in American Samoa, 2010. Emerg Infect Dis. 2013;19(2):324-6.

11. Darcy ACH, Phillips D, Bakote'e B, Stewart T. Solomon Islands dengue seroprevalence study--previous circulation of dengue confirmed. P N G Med J. 2001.

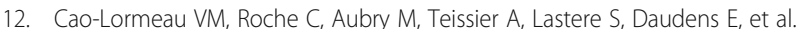
Recent emergence of dengue virus serotype 4 in French Polynesia results from multiple introductions from other South Pacific Islands. PLoS One. 2011;6(12):e29555.

13. Nogareda F, Joshua C, Sio A, Shortus M, Dalipanda T, Durski K, et al. Ongoing outbreak of dengue serotype-3 in Solomon Islands, January to May 2013. Western Pac Surveill Response J. 2013;4(3):28-33.

14. Duffy MR, Chen TH, Hancock WT, Powers AM, Kool JL, Lanciotti RS, et al. Zika virus outbreak on Yap Island, Federated States of Micronesia. N Engl J Med. 2009;360(24):2536-43.

15. Roth A, Hoy D, Horwood PF, Ropa B, Hancock T, Guillaumot L, et al. Preparedness for threat of chikungunya in the pacific. Emerg Infect Dis. 2014;20(8). 
16. Craig AT, Joshua CA, Sio AR, Teobasi B, Dofai A, Dalipanda T, et al. Enhanced surveillance during a public health emergency in a resource-limited setting: experience from a large dengue outbreak in Solomon Islands, 2016-17. PLoS One. 2018;13(6):e0198487.

17. Leparc-Goffart I, Baragatti M, Temmam S, Tuiskunen A, Moureau G, Charrel $\mathrm{R}$, et al. Development and validation of real-time one-step reverse transcription-PCR for the detection and typing of dengue viruses. J Clin Virol. 2009:45(1):61-6.

18. Pyke AT, Daly MT, Cameron JN, Moore PR, Taylor CT, Hewitson GR, et al. Imported zika virus infection from the Cook Islands into Australia, 2014. PLoS Curr. 2014;2:6.

19. Corman VM, Rasche A, Baronti C, Aldabbagh S, Cadar D, Reusken CB, et al. Assay optimization for molecular detection of Zika virus. Bull World Health Organ. 2016:94(12):880-92.

20. Phommanivong V, Kanda S, Shimono T, Lamaningao P, Darcy AW, Mishima N, et al. Co-circulation of the dengue with chikungunya virus during the 2013 outbreak in the southern part of Lao PDR. Trop Med Health. 2016:44:24.

21. Tom H. BioEdit version 7.05; 2005.

22. Kumar S, Stecher G, Tamura K. MEGA7: Molecular Evolutionary Genetics Analysis Version 7.0 for bigger datasets. Mol Biol Evol. 2016;33(7):1870-4.

23. Tam CC, Tissera $H$, de Silva AM, De Silva AD, Margolis HS, Amarasinge A. Estimates of dengue force of infection in children in Colombo, Sri Lanka. PLoS Negl Trop Dis. 2013;7(6):e2259.

24. Whitaker HJ, Farrington CP. Estimation of infectious disease parameters from serological survey data: the impact of regular epidemics. Stat Med. 2004;23(15):2429-43.

25. Senn N, Luang-Suarkia D, Manong D, Siba PM, McBride WJ. Contribution of dengue fever to the burden of acute febrile illnesses in Papua New Guinea: an age-specific prospective study. Am J Trop Med Hyg. 2011;85(1):132-7.

26. Dhar-Chowdhury P, Paul KK, Haque CE, Hossain S, Lindsay LR, Dibernardo A, et al. Dengue seroprevalence, seroconversion and risk factors in Dhaka, Bangladesh. PLoS Negl Trop Dis. 2017;11(3):e0005475.

27. Alera MT, Srikiatkhachorn A, Velasco JM, Tac-An IA, Lago CB, Clapham HE, et al. Incidence of dengue virus infection in adults and children in a prospective longitudinal cohort in the Philippines. PLoS Negl Trop Dis. 2016; 10(2):e0004337.

28. Vongpunsawad S, Intharasongkroh D, Thongmee T, Poovorawan Y. Seroprevalence of antibodies to dengue and chikungunya viruses in Thailand. PLoS One. 2017;12(6):e0180560.

29. Reich NG, Shrestha S, King AA, Rohani P, Lessler J, Kalayanarooj S, et al. Interactions between serotypes of dengue highlight epidemiological impact of cross-immunity. J R Soc Interface. 2013;10(86):20130414.

30. Adams B, Holmes EC, Zhang C, Mammen MP Jr, Nimmannitya S, Kalayanarooj $\mathrm{S}$, et al. Cross-protective immunity can account for the alternating epidemic pattern of dengue virus serotypes circulating in Bangkok. Proc Natl Acad Sci U S A. 2006;103(38):14234-9.

31. Gordon A, Gresh L, Ojeda S, Katzelnick LC, Sanchez N, Mercado JC, et al. Prior dengue virus infection and risk of Zika: a pediatric cohort in Nicaragua. PLoS Med. 2019;16(1):e1002726.

32. Pyke AT, Moore PR, Hall-Mendelin S, McMahon JL, Harrower BJ, Constantino TR, et al. Isolation of Zika virus imported from Tonga into Australia. PLoS Curr. 2016;7:8.

33. Guzman MG, Alvarez M, Halstead SB. Secondary infection as a risk factor for dengue hemorrhagic fever/dengue shock syndrome: an historical perspective and role of antibody-dependent enhancement of infection. Arch Virol. 2013;158(7):1445-59.

34. Guzman MG, Kouri, G., Vazquez, S., Rosario, D., Bravo, J. et al. . DHF Epidemics in Cuba, 1981 and 1997: some interesting observations: WHO Regional Office for South-East Asia; 1999.

35. Flipse J, Wilschut J, Smit JM. Molecular mechanisms involved in antibodydependent enhancement of dengue virus infection in humans. Traffic. 2013; 14(1):25-35.

36. Liu LT, Dalipanda T, Jagilly R, Wang YH, Lin PC, Tsai CY, et al. Comparison of two rapid diagnostic tests during a large dengue virus serotype 3 outbreak in the Solomon Islands in 2013. PLoS One. 2018;13(8):e0202304.

37. Kosasih H, Alisjahbana B, Widjaja S, Nurhayati, de Mast Q, Parwati I, et al. The diagnostic and prognostic value of dengue non-structural 1 antigen detection in a hyper-endemic region in Indonesia. PLoS One. 2013;8(11): e80891.

38. Ramirez AH, Moros Z, Comach G, Zambrano J, Bravo L, Pinto B, et al. Evaluation of dengue NS1 antigen detection tests with acute sera from patients infected with dengue virus in Venezuela. Diagn Microbiol Infect Dis. 2009;65(3):247-53.

39. Moore PR, van den Hurk AF, Mackenzie JS, Pyke AT. Dengue viruses in Papua New Guinea: evidence of endemicity and phylogenetic variation, including the evolution of new genetic lineages. Emerg Microbes Infect. 2017;6(12):e114.

40. Waman VP, Kolekar P, Ramtirthkar MR, Kale MM, Kulkarni-Kale U. Analysis of genotype diversity and evolution of dengue virus serotype 2 using complete genomes. PeerJ. 2016;4:e2326.

41. Tian H, Sun Z, Faria NR, Yang J, Cazelles B, Huang S, et al. Increasing airline travel may facilitate co-circulation of multiple dengue virus serotypes in Asia. PLoS Negl Trop Dis. 2017;11(8):e0005694.

\section{Publisher's Note}

Springer Nature remains neutral with regard to jurisdictional claims in published maps and institutional affiliations.
Ready to submit your research? Choose BMC and benefit from:

- fast, convenient online submission

- thorough peer review by experienced researchers in your field

- rapid publication on acceptance

- support for research data, including large and complex data types

- gold Open Access which fosters wider collaboration and increased citations

- maximum visibility for your research: over $100 \mathrm{M}$ website views per year

At BMC, research is always in progress.

Learn more biomedcentral.com/submissions 